INDIAN CLASSICAL MUSIC : AN OBJECTIVE SLUICE IN THE REALMS OF MIND- BODY MEDICINE

\author{
Dr. VelloreA.R.Srinivasan, Professor, \\ Department of Biochemistry and adjunct faculty, \\ Centre for Music Therapy Education and Research (CMTER),
}

Sri Balaii Vidyapeeth - Mahatma Gandhi Medical College and Research Institute Campus

Pillaiyarkuppam, Puducherry - 607403, India

i

\section{HISTORICAL PERSPECTIVES}

Mind -body medicine employs the unique power of thoughts and emotions. This enables us to influence physical health that eventually leads to holistic health, wherein both physical and mental health acquire optimal attributes ${ }^{1}$.

It must be mentioned that several healing practices of the past including our Ayurvedic medicine had convincingly demonstrated the linkbetween the mind and the body ${ }^{2}$.In the West, the prevalent notion was that mind and body were separate entities and this concept essentially surfaced during the Renaissance and Enlightenment eras. A plethora of scientific and technological discoveries laid emphasis on diseasebased models, gross pathological changes, and curative modalities. But, in the twentieth century, mind and body in health and disease made an objective and evidence based reappearance. Several cardinal discoveries, with reference to pain perception, control and effects of stress on health opened newer vistas in the domains of complementary and alternative medicine ${ }^{3}$.

Herbert Benson assigned the term relaxation response, while studying how meditation could influence blood pressure. In 1975, the well-knownpsychologist Robert Ader showed that mental and emotional cues could affect the immune system, which in turn largely regulates holistic health ${ }^{4}$.

One of the earliest known documented references in the realms of music therapy dates back to 1789 . Incidentally, it appeared in a Columbian Magazine titled "Music Physically Considered." However, the medical fraternity had to wait till 1804, when the therapeutic value of music made its great appearance in medical dissertation, the first published one by Edwin Atlee. Soon, one more dissertation compiled by Samuel Mathews in the year 1806 came into the scene. The credit must however go to Dr. Benjamin Rush, a physician and psychiatrist who was a strong votary of using music to treat medical diseases. Atlee and Mathews were his students. Thus, music therapy saw its genesis in the realms of mind body medicine. However, mention must be made of the fact that the moorings in mind-body medicine, as related to music therapy dates back to the Ayurveda era in Indian history. In the present context, the equivalent is salutogenesis. Music medicine and therapy of our sub continent is synonymous with Ayurvedas.

AYU and VEDA which literally meanthe knowledge of long life is constituted by the single wordAyurveda . This represents the oldest existing medical system of India and has flourished over 5000years, because of its fundamental principles which acquire relevance in the modern era. Ayurveda has a holistic preventive and curative approach where the goal is not only to curtail the disease but also to maintain the Physical, mental and spiritual health of a healthy person. In the present context, the equivalent is salutogenesis. Music medicine and therapy of our sub continent is synonymous with Ayurveda ${ }^{6}$.

Techniques in mind body medicine: To train the mind so as to focus on the body without distraction is an essential tenet. In this state of focused concentration, the client/patient mayenvisage improvement in health. 
Of a variety of techniques employed in mind body medicine, mention must be made of the following:-

Biofeedbacktrains one to regulate processes that normally occur involuntarily. These processes can be measured and depicted on a monitor whichprovides feedback about the internal environs of the body ${ }^{7}$. Based on these, it is possible to use CAM .Biofeedback has been received wellin a number of conditions including migraine, headache and chronic pain.Cognitive behavioral therapy is one more modalitythat helps enable people to recognize and attenuate harmful thoughts. Of all these, music therapy holds much promise and in recent years has been promulgated on a large scale the world over.

The mind-body nexus and Relaxation techniques:Hippocrates, the Greek physician of the Age of Pericles eulogized mind body medicine. He made the profound statement" The natural healing force within each one of us is the greatest force in getting well." This forms the essential nucleus of mind body medicine, which in recent years has been creating a lot of interest and impetus in the world of medicine?

When a person is physically or emotionally stressed, the body releases stress hormones that can affect several organs and systems. Depression, anxiety and emotional distress/turmoil may diminish the body's natural capacity to heal and precisely for this reason, emotions have been linked to diseases. The goal of mind-body techniques is to get the body and mind to relax and to reduce the levels of stress hormones in the body, so that the immune system is in a vantage position to combat illness. Mind-body techniques may help treat many different diseases, including several psychosomatic conditions. Some of the medical conditions include hypertension, ischaemic heart diseases, insomnia, irritable bowel disease etc. In recent years, such techniques have found use in palliative care too. However, it is to be noted that Mind-body medicine yields optimal results when combined with the conventional medical care.

There are 3 major types of relaxation techniques that have been recognized in mind body medicine, viz. autogenic training, which uses both visual imagery and body awareness to create a deep state of relaxation. Guided imagery and music (GIM) is presently acquiring enhanced significance in music therapy. GIMis considered as a psychodynamic and multimodal unique therapy that incorporates listening to music, while the client is in a deeply relaxed state.
Thisprovokes imagery, memories and feelings that eventually help the client comprehend several facets of life, but from a holistic perspective. Western classical music has been used widely in GIM $^{8,9}$. However, Indian Classical music which boasts of a rich past, present and future should be considered as a rightful candidate for use in GIM. Progressive muscle relaxation and meditation are two other modes of relaxation techniques and music therapy/medicine has quite a lot of inputs in this arena.

Spiritual healing and mind body medicine :Providing compassionate care to the patient essentially means that the care provider should alleviate suffering, be it physical, emotional or spiritual. Spiritual healing is yet another mode that has been assuming greater relevance in recent years and it is in this context that music acquires the dimension of a healer and more so, in the light of the fact that Indian Classical Music has got a major spiritual component that is inherent ${ }^{10}$.

Though a host of Mind-body techniques are presently available and are principally aimed at relaxation, stress attenuation, endurance, alleviation of tension and pain, and more importantly decreasing the requirements of pharmacological preparations, music therapy is objective and alleviates symptoms of anxiety and depression .

\section{THE UNIOUENESS OF INDIAN CLASSICAL MUSIC}

Indian classical music is characterized by its elaborate, expressive and emphatic nature. Each of the Indian Classical mode is referred to as a rag or raga. The word 'raga' in Sanskrit means 'to please'. Each raga is typified by the presence of an ascending scale designated as arobana and a descending scale referred to as the avarohana. Akin to the Western classical music, the classical music of India segregates the octave into 12 semitones. Of these, $\mathrm{Sa}$, RiGa Ma Pa DhaNi denote the basic notes. These notes are similar to Western music's Do Re MiFa So La Ti[ ${ }^{11}$

Basically, Indian Classical music has two idioms, namely Carnatic or karnatik and Hindustani. The Karnatikmusic has 72 main or parent ragas designated as melakarta and hundreds of ragas (musical modes) that are born out of these parent ragas-the janyaragas. Hindustani music which is prevalent in the relatively northern areas of India follows a unique system, known as that. There are basically only 10 thats $^{12}$ 
Indian music uses intonation tuning, unlike most modern Western classical music, thereby lending itself to greater improvisation. Indian classical music is monophonic . Each of the ragas has select phrases known as jeevaswar(a). Subtle oscillations of select notes in a musical mode, synonymous with the term gamaka or gamakendear Indian Classical music to experimentation that could effectively be used in music therapy ${ }^{13}$. In other words, Indian classical music depends upon melodic movement, that is, the occurrence of tones or musical notes to create a single line of tune, rather than upon harmony, which uses several lines of melody in pleasing contrast with each other, as is common in Western music. This facet of Indian classical music comes in handy while extending its services to the cause and practice of adjuvant music therapy.

\section{INDIAN CLASSICAL MUSIC AND ITS EVOLUTION WITH RESPECT TO THERAPY}

Indian classical music therapy is an excellent complementary therapeutic modality that works on the principle of Mind- Body medicine. It not only rediscovers, but also enhances the inbuilt natural healing process. The proven benefits of classical Indian music rests largely on its ability to create beneficial effects. Classical music is more than an entertainment. It is physically, psychologically, emotionally and even spiritually uplifting. Indian classical music forms an adjuvant therapy and has been inherited from our ancestors. The Vedas or holy scriptures of the Hindus have had reference to music. Of the four Vedas, music is believed to have evolved from Sama Veda. GandharvaVeda, which is a constituent of SamaVeda, is regarded as the Veda of Music ${ }^{14}$.

Evidences are available to cite that the 72 ragascan influence the cardinal 72 nerves in the human body. Singing or performing a raga or even listening to it can influence mind and body. However, it is imperative that the performer or the therapist applies principles in compliance withthe purity in pitch and effective use of intonations/ gamaks etc. ${ }^{15}$

The concept of Music Therapy in India is unique and is absolutely dependent on the use of correct/ appropriate intonation and the right mix of music. The Classical ragas are based on select notes. Since there are several musical modes or ragas in the Indian classical music, each having its inherent mood and texture, the possibility of using a particular raga as a therapeutic modality for a particular disease becomes an objective reality. Different types ofragas are applied in each of the different disorders/ diseases, a pronounced feature that needs to be taken cognizance of ${ }^{16}$.

\section{THE ROLE OF AUTONOMIC NERVOUS SYSTEM IN MUSIC THERAPY}

The autonomic nervous system (ANS) acts as a bridge between the central nervous system (CNS; brain and spinal cord) and the major peripheral organs and organ systems. The organ systems of cardinal significance include circulatory, digestive, endocrine, integumentary, reproductive, respiratory etc. The ANS has two major branches - a sympathetic branch, associated with energy mobilization, and a parasympathetic branch concerned with vegetative and restorative functions ${ }^{17}$.

Humanbeings interact with music, both consciously and subconsciously, at behavioral, emotional, and physiological levels. Pertaining to experimental studies, it is important to explore how specific features of Indian classical music (e.g., itsraga, beat, tempo, or pitch level) trigger neurophysiological, psychophysiological, emotional, and behavioral responses ${ }^{18}$. On the contrary, with respect to interventions with physiological targets, it is important to consider that ANS dysfunction is mediated by the CNS, and that treatment of the former should be sensitive to the state of the latter. This concept needs to be effectively capitalized upon, while considering music therapy.

The use of ragas or musical modes is linked to the daily cyclical changes that occur in our own body and mind which are constantly undergoing subtle physiological changes. This could be capitalized in view of the fact that the Indian Classical Music modes are available to reflect the cyclical changes and perceptions

\section{THE CAKRA SYSTEM AND INDIAN CLASSICAL MUSIC IN THERAPY: AN INSTANCE OF MIND -BODY MEDICINE}

In the Indian scenario, music therapy has been allowed to evolve right from the Ayurveda age by facilitating its proximity to mind body medicine. There are seven chakras or centers in our body through which energy flows-the harbinger of mind body medicine ${ }^{19}$.

The Omkar Therapy is regarded as a component of the Indian music that envisages the improvement of holistic health through music. It is interesting to note that a combination of specific notes or melodic scales can act on a specific chakra and bring typical effect. 
The RootCakra is synonymous withour feeling of being grounded. Sacralcakra enables us to endear with others and acquire new experiences. The Solar Plexus cakraenables us to be in control of our lives. The heart cakradenotes ability to like/love. Whereas, the throat cakra defines our ability to communicate, the third eye cakracentres around our ability to envisage the bigger picture, Thecrown cakra is the ultimate as it signifies the spiritual component. Thus, the cakra system of healing can very well explain the role of using classical Indian music as healing adjuvants ${ }^{19}$

The variegated potentials of Indian music therapy: It is believed that the chakras enjoy nexus with different organs. As a result, any aberration in the functioning of an organcreatesan imbalance in the person. Different effects are perceived that vary with physiological psychological and emotional factors. Each effect is an attribute of the flux in mind body medicine. Furthermore, it is a matter of revelation that Indian classical music produces different physical, physiological and emotional contours in the listener ${ }^{20}$.

When the energy, typical vibrations and frequency of Indian classical music match with those of the chakras, they get activated. This facilitates Kundalinior primal energy that is located in the base of the spine to rise upward. While rising, the Kundalini nourishes the chakras and provides proper energy to them. In view of the fact that organs are connected with the chakras, they also acquire the appropriate and adequate energy required. Once the Kundalini finds its path to rise, it rises and pierces through the fontanelle bone area facilitating connection with the cosmic energy. This activation process is synonymous with the use of music as an adjuvant therapeutic agent, though it is categorically stated that more of evidence based and objectivised research inputs need to be acceded to the armamentarium of adjuvant medicine 21 .

The use of ragas or musical modes is linked to the daily cyclical changes that occur in our own body and mind which are constantly undergoing subtle physiological changes. This could be capitalized in view of the fact that the Indian Classical Music modes are available to reflect the cyclical changes and perceptions

Putative effects of some ragas as therapeutic agents ${ }^{22}$ :

The ragaYamanin the Hindustani idiom that resembles the $65^{\text {th }}$ melakartaraga Mechakalyani of Karnatik music has a power of sustenance by activating the Swadisthan or sacralcakra.This raga promotes internal meditation and stabilizes the vagal tone.

One of the most popular ragas that are in vogue in bothKarnatik and Hindustani idioms of Indian classical music is Abhogi. This raga enables the activation of the cakra in the navel region and thus stimulates the digestion process.

RagaShyamKalyan belonging to the Kalyanthaatin the Hindustani idiom helps to activate Mooladharacakra, thereby allowing the primal energy- theKundalini to rise gently and naturally, for conferring optimal benefits.

RagaBhairav and raga Durga in the Hindustani idiom of Classical Indian Music activate the heart cakra, thereby conferring equipoise and optimization of heart rate variability (HRV), by taking into due consideration the sympathetic and parasympathetic nervous inputs of the autonomic nervous system for optimization.

It has to be reiterated that more of experimental/ interventional studies on volunteers/ clients need to be documented in PUBMED and other established databases, although there are isolated reports of such studies cited in the literature.

\section{INDIAN CLASSICAL MUSIC AND EMOTIONS}

The musical notes are shadja, rishaba, gandhara, madhyama, panchama, dhaivata and nishada, while the moods are shringar (love), hasya (laughter), karuna (compassion), vira (heroism), raudra (wrath), bhayanaka (fear), bibhatsa (disgust) and adbbuta (wonder). Hence, the classical music of India endears itself with the emotions themselves, that are eventually regulated by the limbic component of the human brain. The madhyama and panchama notes are used to create a feeling of love or laughter. Gandhara and nishadaare evocative of compassion, while fear and disgust are aptly conveyed by resorting to the use of dhaivata. Shadja and rishabacreate a mood of anger, courage or wonder ${ }^{23}$

The reaction to the music one listens to is both the primary effect of the notes and their systematic arrangement, and a secondary effect of the thoughts and moods evoked by the primary reaction. The brain processes music in a complex and yet subtle way, using several different modes, such as perceptual, emotional, cognitive, motor and autonomic. The sound waves impinge on the cochlea of the ear to produce effective signals, which reach the brainstem and finally the 
auditory cortex of the brain. There are also additional areas involved in music perception, which help to define the pitch, the timbre or quality, the rhythm, the roughness and the loudness or intensity of the music ${ }^{24}$

Other areas, such as the amygdala and cingulate gyrusmay be responsible for the emotional reaction to music. Music which produces pleasure activates the frontal cortex, while the temporal lobe is active when listening to unpleasant music. Ironically, sadness in music is sometimes a source of defined pleasure as well as pain. This assumes relevance in music therapy ${ }^{25}$.

\section{CONCLUSION}

- Raga based Indian music therapy is set to meet individual needs. Generalisation is not possible

- Unlike other forms of music used in adjuvant therapy, Indian classical music has the spiritual component adhered to itself
- Raga based approach produces characteristic and nodal changes in the body which go a long way in alleviating stress and anxiety

- Indian music therapy is believed to enhance concentration and attention span

- Raga based music can be tailor made for the client, in view of the several choices that are made available. Typical musical modes are available such as those based on pentatonic, hexatonic scales etc.

- More evidence based research has to be summoned, if a few subjective aspects in Indian Classical Music Therapy need to essentially metamorphose into an objective sluice in the realms of Mind-body medicine.

\section{REFERENCES}

1. Barrows KA , Jacobs BP. Mind-body medicine. An introduction and review of the literature.MedClin North Am. 2002 Jan;86(1):11-31

2. Mukherjee PK , Harwansh RK, Bahadur S , Banerjee S , Kar A , Chanda J , Biswas S , Ahmmed SM , Katiyar CK. Development of Ayurveda - Tradition to trend.J Ethnopharmacol.2016 Sep 12.pii: S0378-8741(16)30782-6

3. Cheung CK, Wyman JF, HalconLL.Use of complementary and alternative therapies in community-dwelling older adults.JAltern Complement Med. 2007 Nov; 13(9):997-1006

4. Stahl JE, Dossett ML, LaJoie AS, Denninger JW, Mehta DH, Goldman R, Fricchione GL, Benson H.Relaxation Response and Resiliency Training and Its Effect on Healthcare Resource Utilization.PLoS One. 2015 Oct 13;10(10):e0140212. doi: 10.1371/journal.pone.0140212. eCollection 2015

5. Nagarajan K, Srinivasan TM, Nagendra HR. Music therapy based on individual's 'biological humor' -With reference to medical astrology: a review. http://iamj.in/posts/images/upload/528_543.pdf

6. Mind-body medicine.http://umm.edu/health/medical/altmed/treatment/mindbody-edicine

7. Rausa M ,PalombaD, Cevoli S, Lazzerini L, Sancisi E, CortelliP,PierangeliG.Biofeedback in the prophylactic treatment of medication overuse headache: a pilot randomized controlled trial.J Headache Pain. 2016 Dec;17(1):87. Epub 2016 Sep 22

8. Fasting and purification. http://www.greekmedicine.net/hygiene/Fasting_and_Purification.html

9. Beebe LH, Wyatt TH. Guided imagery and music: using the Bonny method to evoke emotion and access the unconscious. J PsychosocNursMent Health Serv. 2009 Jan; 47(1):29-33

10. Music Therapy for Meditation. http://www.sahajayogaportal.org/en/music-therapy.html

11. Ludwig Pesch. The Oxford Illustrated Companion to South Indian Classical Music, Oxford University Press

12. Bor, Joep. The Rāga Guide, Charlottesville,Virginia: Nimbus Records ( 1999)

13. Sambamoorthy P. South Indian Music - Vol I, Chennai, India: The Indian Music Publishing House, p. 18.2005

14. Guy Beck . Sonic Theology: Hinduism and Sacred Sound, University of South Carolina Press, ISBN 978-0872498556, pages 107-108. 1993

15. Indian music : a therapeutic heritage-1. http://ayurveda-foryou.com/music/therapeutic-music1.html

16. Raga music therapy. http://www.pilu.in/raga-therapy.html

17. Okada K, Kurita A, Takase B, Otsuka T, Kodani E, Kusama Y, Atarashi H, Mizuno K. Effects of music therapy on autonomic nervous system activity, incidence of heart failure events, and plasma cytokine and catecholamine levels in elderly patients with cerebrovascular disease and dementia.Int Heart J. 2009 Jan;50(1):95-110

18. Banerjee A, Sanyal S, Sengupta R, Ghosh D. Music and its Effect on Body, Brain/Mind:A Study on Indian Perspective by Neurophysical Approach. http://blood-pressure.imedpub.com/

19. Shang C. Emerging paradigms in mind-body medicine.J Altern Complement Med. 2001 Feb;7(1):83-91

20. Moore MM. Comparison of the Strength of Harmony, Melodic Line, Rhythmic Variation, and Expressive Elements in Influencing Emotional Judgment in Music. http://scholarworks.wmich.edu/cgi/viewcontent.cgi?article=1454\&context=masters_theses

21. de Castro JM. Meditation has stronger relationships with mindfulness, kundalini, and mystical experiences than yoga or prayer.Conscious Cogn. 2015 Sep;35:115-27 doi: 10.1016/j.concog.2015.04.022. Epub 2015 May 22

22. Sanivarapu SL.India's rich musical heritage has a lot to offer to modern psychiatry.Indian J Psychiatry. 2015 Apr-Jun;57(2):210-3. doi: 10.4103/0019-5545.158201

23. Mathur A, Vijayakumar SH, Chakrabarti B, Singh NC. Emotional responses to Hindustani raga music: the role of musical structure. Front Psychol. 2015 Apr 30;6:513. doi: 10.3389/fpsyg.2015.00513. eCollection 2015.

24. Thomas L. Indian Music Therapy.http://www.news- medical.net/health/Indian-Music-Therapy.aspx

25. Nizamie SH, Tikka SK. Psychiatry and music. Indian J Psychiatry. 2014 Apr-Jun; 56(2): 128-140. doi: 10.4103/0019-5545.130482 